\title{
Unusual Presentation and Treatment of Basal Cell Carcinoma with Novel Drug Vismodegib
}

\author{
William J. Sanders, $\mathrm{BS}^{1 *}$, and William E. Freeman, $\mathrm{MD}^{1}$ \\ College of Osteopathic Medicine, Philadelphia, USA
}

"Corresponding author: William J. Sanders, BS,1485 Leverette Rd. \# 2302 Warner Robins, GA 31088, College of Osteopathic Medicine (PCOM), Philadelphia,Tel: (318)801-8668;

E-mail:williamsan@pcom.edu

Received Date: $07^{\text {th }}$ February 2017

Accepted Date: $19^{\text {th }}$ May 2017

Published Date: $26^{\text {th }}$ May 2017
Citation: Sanders WJ, Freeman WE (2017) Unusual Presentation and Treatment of Basal Cell Carcinoma with Novel Drug Vismodegib. Enliven: Clin Dermatol 3(1): 001.

Copyright: @ 2017 Dr. William J. Sanders. This is an Open Access article published and distributed under the terms of the Creative Commons Attribution License, which permits unrestricted use, distribution and reproduction in any medium, provided the original author and source are credited.

Keywords: Vismodegib;Basal;Cell;Carcinoma;Hedgehog

Abbreviations: BCC: Basal Cell Carcinoma; SMO: Smoothened Homolog

\section{Introduction}

Basal Cell Carcinoma (BCC) is a superficial cancer of the skin that occurs on sun-exposed areas $[1,2]$. It is more prevalent in those with pale skin, blue eyes, and of Northern European Descent, those older than 60, and more common in men than women [3,4]. It arises from the basal layer of the epidermis. There are many different types of BCC, including nodular, superficial, pigmented, and sclerosing or morpheaform. The most common type, however, is nodular BCC [1]. It presents as a pearly, pink papule with rolled borders that can have some overlying telangiectasia. It can also have some ulceration at the base. These classically occur on the upper lip and nose, particularly on the left side due to exposure while driving a vehicle. It can also present in the older adult who is worried about a new pimple even though they should be too far in age for acne. These lesions are usually caught early enough and are shaved or punched for biopsy. If biopsy shows $\mathrm{BCC}$, the Dermatologic surgeon will perform an exision, Moh's Micrographic Surgery, or other surgical and non-surgical options. The patient would typically follow-up every 6 months for 2 years [2]

This is a normal option for those who have insurance and funds to see and pay for dermatologic treatment. However, not everyone has the ability to do this. For the unfortunate who are homeless and or/without job and insurance or money for self-pay, sometimes tumors are neglected. If left alone, the tumor can gradually grow and cause structural, emotional, and socioeconomic problems. This case represents a neglected BCC that grew for many years and became intermittently infected and inflamed so badly that the patient struggled to be hired for any jobs and eventually became homeless. Essentially his tumor prevented him from providing for himself and thus began a spiral which left him unable to pay for treatment as the tumor grew larger. However, he was given new hope with the novel drug Vismodegib.

\section{Case Presentation}

The patient is a 55 -year-old white male who presented to the dermatology clinic in dire need of a consultation for a large, nodular, pearly white lesion on the right brow and forehead. The lesion was draining a fowlsmelling discharge which was green in color. He has a past medical history of Basal Cell Carcinoma (BCC) for the past 20 years. He had not been able to obtain treatment for it because he had been mainly homeless. Although he occasionally has worked in construction, he was homeless at presentation. He had previously obtained an MRI and biopsy of the lesion when he had been worked up in various hospitals. The lesion would periodically become infected which caused him to present to the hospital. The MRI indicated no metastasis, so the patient was given antibiotics and referred to a dermatologist who was my preceptor at the time.

Because he was not able to ever treat the lesion, it had grown tremendously over the past 20 years. Usually, patients with BCC get treatment and the lesion does not grow to be large. However, this patient unfortunately had no financial means with which to get treatment for the cancer. The lesion covered his right brow and forehead region to the point where he had to wear a stocking cap in order to cover it up. This, along with the unavoidable lower level of personal hygiene that accompanies living homeless, caused the patient to have recurrent infections of the ulcerated lesion and a great deal of lowered self-esteem and depression. Figure 1 shows the patient at presentation. 


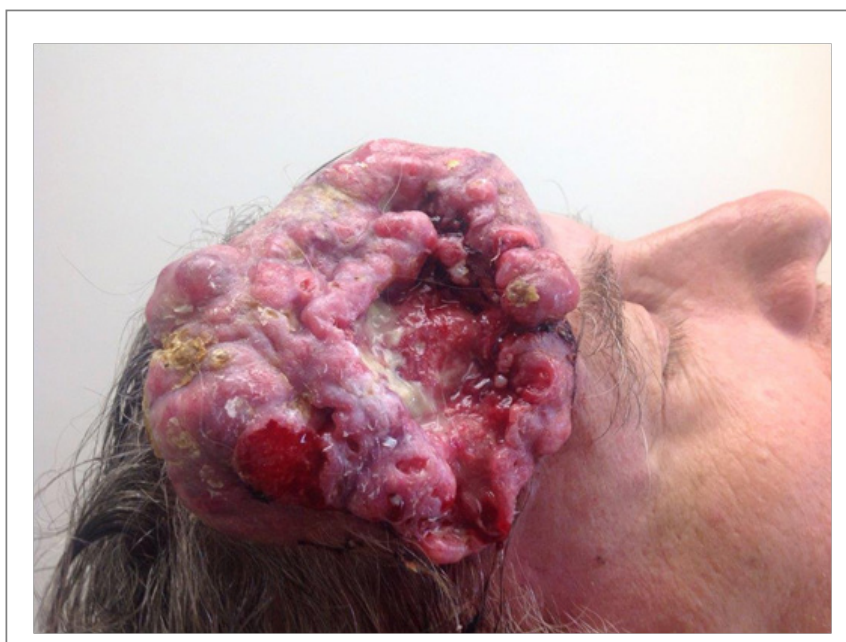

Figure 1: Before treatment with Vismodegib

Upon confirmation of the pathology report, the dermatologist who owned the clinic said that this was the largest BCC that has shown up at the clinic. The pathology report allowed us to try a novel treatment, a drug called Vismodegib. The patient took $150 \mathrm{mg}$ by mouth, once daily. Vismodegib has a specific mechanism of action, which will be discussed later. The patient was provided with a manufacturer's discount program setup via the clinic, because he would have otherwise not been able to afford treatment.

After 1 month of oral Vismodegib treatment, the patient presented to the clinic up for a follow- up, and the results were remarkable. The lesion that had previously projected outwardly from his brow and forehead had become drastically smaller. Figure 2 and Figure 3 show the improvement after only 1 month.

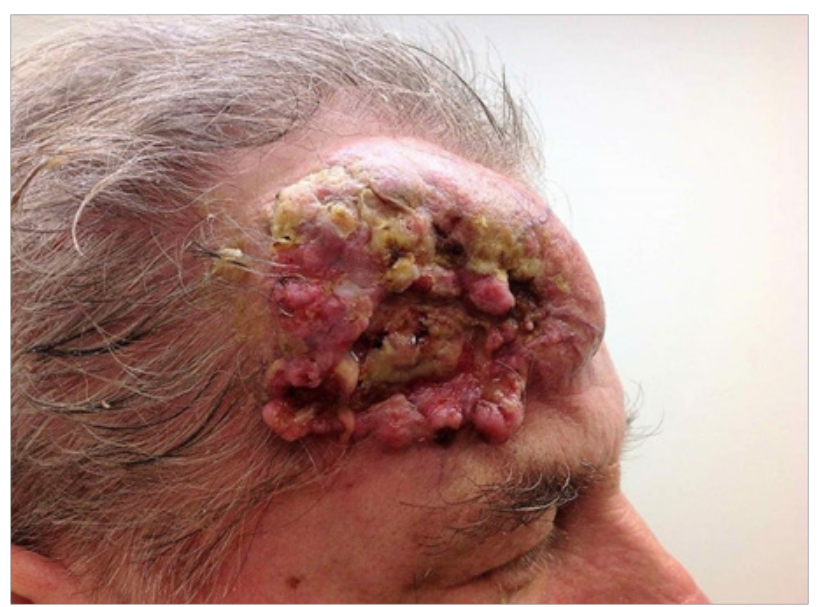

Figure 2: One month of treatment with Vismodegib

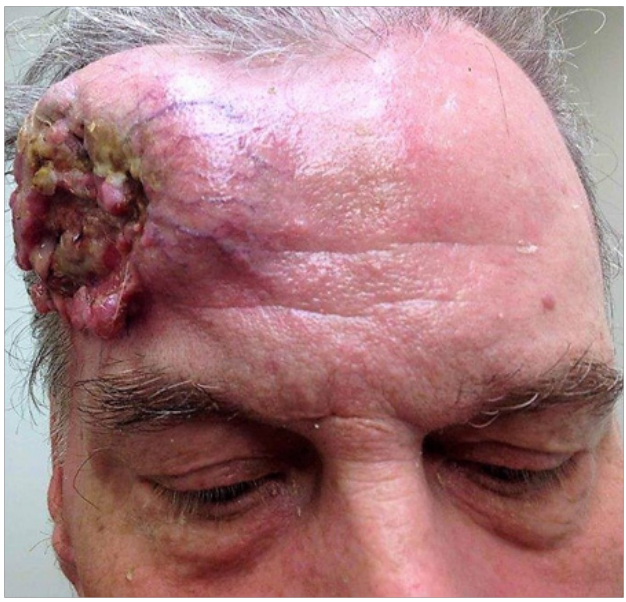

Figure 3: One month treatment with Vismodegib

With one more month of treatment (a total of 2-months), the cancerous lesion had regressed to the point of being relatively flat again. The patient's overall attitude and self-esteem had improved dramatically. He was now able to wear baseball caps, which made him happy that he did not have to cover the lesion up with a stocking cap during all seasons. Figure 4 and Figure 5 show the patient two months after initiating treatment.For 20 years, this patient was living with a growing cancer on his head, and with a short trial of Vismodegib, the lesion shrunk to a very small size. The next step in the treatment of this patient is to follow up a few months later and then do radiation therapy. This was an unusually large BCC that had been neglected for far too long. If financial burden is ever the cause of impediment to the treatment of a patient's condition, effort should be given to alleviate these restrictions. With the help of the manufacturer and in coordination with the dermatologist, this patient was able to obtain an expensive drug which shrunk his cancer by $90 \%$. Let this case report provide clinical evidence that even neglected BCC of any size can be treated with Vismodegib.

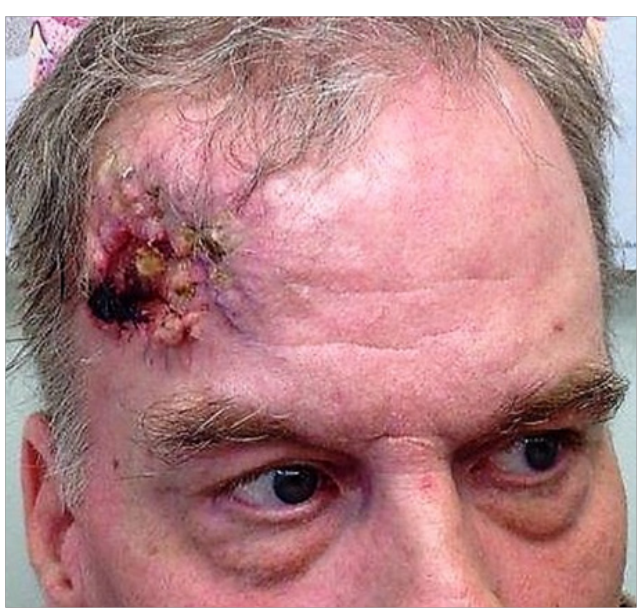

Figure 4: Two months of treatment with Vismodegib 


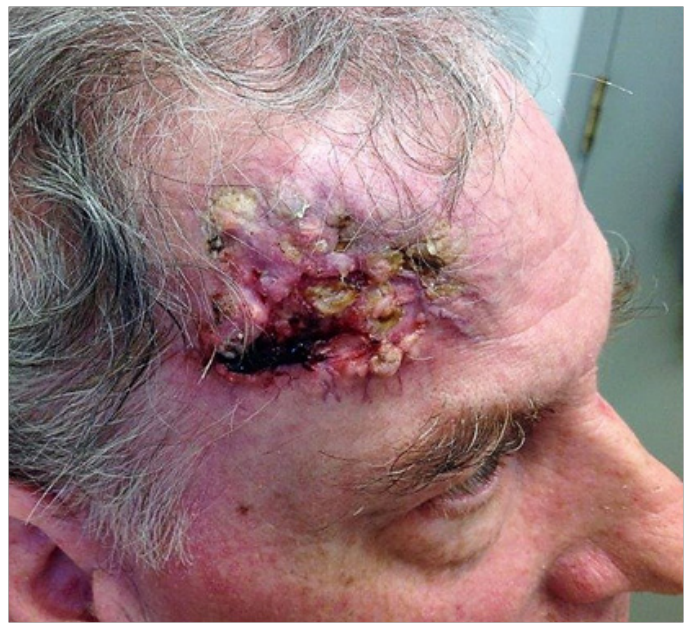

Figure 5: Two months of treatment with Vismodegib

\section{Discussion}

Among the different risk factors and predispositions to getting BCC-such as fair skin, blue eyes, northern European ancestry, and sun exposurethere are also genetic risk factors. One such predisposition is having a mutation in the PTCH gene, a tumor suppressor gene that is involved in the hedgehog pathway [5]. In the hedgehog pathway, a cell surface receptor called smoothened homolog (SMO) starts the hedgehog pathway of cellular growth. PTCH inhibits SMO to regulate this proliferation. However, the hedgehog ligand inhibits PTCH. Essentially, there is inhibition of PTCH's inhibition of a cellular growth initiator, SMO. This double negative action allows SMO to carry out its actions in the hedgehog pathway, thus causing cellular proliferation and increased chance of BCC.

In recent years, a new drug has come out to combat this molecular process. Vismodegib inhibits SMO, which prevents the downstream effect of the hedgehog pathway-induced cellular growth. By inhibiting SMO, the hedgehog pathway is halted [6]. Vismodegib has been shown in clinical trials to be effective for local and locally advanced BCC, but it has been shown to be less effective in those who have resistant BCC's [7]. In the case of our patient who had a gradually enlarging tumor for 20 years, the results of taking Vismodegib daily orally for his BCC were remarkable. In just a short period of time, this drug improved his health, his outlook on his condition, his ability to have a new lease on life with new job prospects, as well as his overall happiness. Surgery would not have been possible on this patient because of the margins, so electing to include this patient in a trial of Vismodegib was the best possible choice. The patient and the Dermatologist were thrilled with the results. The discovery of hedgehog pathway's involvement in BCC has given us great insight into the genetic nature of the cancer as well as the pharmacotherapeutic possibilities that are always advancing in medicine. This represents a novel treatment for the neglected and grossly enlarged case of the most common skin cancer in the world. More studies will need to be conducted on the long-term benefits of Vismodegib with local, metastatic, and refractory BCC, but this case provided clinical evidence that Vismodegib is an efficacious viable option.

\section{References}

1. Telfer N, Colver G, Morton C (2008) Guidelines for the management of basal cell carcinoma. Br J Dermatol159:35-48.

2. Eskiizmir GCB, Cingi C (2012) Nonmelanoma Skin Cancer of the Head and Neck: Current Diagnosis and Treatment. Facial PlastSurgClin North Am 20:415-417.

3. Dam RMV, Huang Z, Rimm EB, Weinstock MA, Spiegelman D, et al. (1999) Risk Factors for Basal Cell Carcinoma of the Skin in Men: Results from the Health Professionals Follow-up Study. Am J Epidemiol150:459-468

4. Vitasa BC, Taylor HR, Strickland PT, Rosenthal FS, West S, et al. (1990) Association of nonmelanoma skin cancer and actinic keratosis with cumulative solar ultraviolet exposure in Maryland watermen. Cancer 65:2811-2817.

5. Hahn H, Wicking C, Zaphiropoulos PG, Gailani MR, Shanley S, et al. (1996) Mutations of the Human Homolog of Drosophila patched in the Nevoid Basal Cell Carcinoma Syndrome. Cell85:841-851.

6. Silapunt S, Chen L, Migden MR (2016) Hedgehog pathway inhibition in advanced basal cell carcinoma: latest evidence and clinical usefulness. TherAdv Med Oncol 8: 375-382.

7. Wahid M, Jawed A, Mandal RK, Dar SA, Khan S, et al. (2016) Vismodegib, itraconazole and sonidegib as hedgehog pathway inhibitors and their relative competencies in the treatment of basal cell carcinomas. Crit Rev OncolHematol 98:235-241.

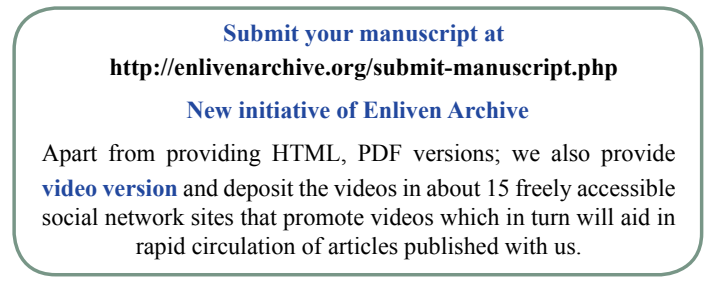

